\title{
ERRATUM
}

\section{A Novel Model for Studying Baculovirus Infection Process}

\author{
Christoph Lindenberger, Lukas Pflug, Holger Huebner, and Rainer Buchholz
}

Received: 11 August 2011 / Revised: 9 October 2011 / Accepted: 11 October 2011

(C) The Korean Society for Biotechnology and Bioengineering and Springer 2012

In the 2012 issue of Biotechnology and Bioprocess Engineering (BBE), an error occurred in the research article: Christoph Lindenberger, Lukas Pflug, Holger Huebner, and Rainer Buchholz (2012) A Novel Model for Studying Baculovirus Infection Process. Biotechnol. Bioprocess Eng. 17: 211-217.

- In the authors's name

Original wording:

Christoph Lindeberger

This should be replaced by:

Christoph Lindenberger

Received: 3 April 2012

Christoph Lindenberger ${ }^{*}$

Friedrich-Alexander Universität Erlangen-Nürnberg Campus Busan, Bioprocess Engineering, Busan 618-230, Korea

Tel: +82-51-899-8000; Fax: +82-51-899-8001

E-mail: christoph.lindenberger@busan.fau.de

Lukas Pflug, Holger Huebner, Rainer Buchholz Friedrich-Alexander Universität Erlangen-Nürnberg, Lehrstuhl für Bioverfahrenstechnik Paul-Gordan Straße 3 Erlangen, Erlangen 91052, Germany 